seaman, aged thirty-one-was not so successful, a small quantity of sugar remaining permanently in the urine, although the general health was perfectly re-established. But this less favourable result was attributable to two causes: first, to the long continuance of the disease (nineteen months after its full development) before the treatment was begun; and, secondly, to the fact that the patient frequently partook, clandestinely, of prohibited articles of food, especially bread, as I afterwards discovered. If the treatment had been tommenced when the disease was first recognised, and the patient had been educated, intelligent, tractable, and capable of appreciating the necessity for a dietetic course of treatment, and, above all, if he had been in a good position in life, instead of returning home to abject poverty, I feel assured the result would have been even more favourable, and probably completely successful.

Dr. Francis Home first indicated the value of an animal diet in the treatment of diabetes mellitus, and it is now nearly three-quarters of a century since the diet he indicated was reduced to a system by Dr. Rollo, in the important work he published on the subject.* During the period which has since elapsed a diet more or less purely animal, as indicated by him, has been recognised as the proper and only available treatment to be employed against this most formidable malady. But the treatment of Rollo, either absolutely followed out or modified by the almission of certain kinds of vegetable food, is not by any means so universally successful as could be wished. The life of the patient is sometimes cut short during the treatment by the sudden accession of inflammatory affections of the abdominal and thoracic viscera. Dr. Bardsley specially directed at. tention to this fact. + Besides, it is exceedingly dificult to enforce a strict adherence to animal food for any length of time; with some individuals, indeed, it becomes almost intolerable. Dr. Rollo himself even lamented that this mode of treatment should be so repulsive to the patient. A purely milk diet, however, is free from these objections; milk being generally relished by the patients, especially at the outset of the treatment, when the thirst is intense. Afterwards they never tire of it, although they generally express a desire for solid food in addition.

From the experience I have already had, I have not the slightest hesitation in asserting that the milk treatment of diabetes is as superior to Rollo's, with its more modern modifications, as Rollo's was to any method previously in use. But it is necessary to add that it must be persevered in methodically and exclusively until convalescence is established. If this rule is not followed from the beginning the result will not be successful.

The efficacy of this treatment need excite no surprise when we know that the disease has hitherto been amenable only to the protracted employment of a dietetic course. The rapidity with which milk acts is truly surprising, twentyfour hours being sufficient for the production of a marked improvement: the quantity and density of the urine suddenly fall, and, pari passu with this change, the thirst and voracious appetite disappear, the skin becomes moist and perspiring, while the symptoms referable to the nervous system are as rapidly relieved; profound refreshing sleep succeeds to the previously sleepless, restless condition, reudered almost intolerable by the incessant thirst. The patient expresses himself thankful for the sudden and unexpected change. In the two cases $I$ have recorded this sudden relief was obtained. I may mention, too, that a third case is now under my care, in which, by the same milk diet, and without any other remedy whatever, the urine fell from 23 pints, sp. gr. 1038, to 9 pints, sp. gr. 1040, in twenty-four hours, and to 6 pints, sp. or. 1038, at the end of the third day of treatment; in other words, there was a diminution of 14 pints of urine and about 19 oz. of sugar in tuenty-four hours, and of 17 pints and about 24 oz. of sugar in three days. A result like this seems almost incredible; but I may add that this astonishingly rapid improvement in the urine was accompanied by a correspondingly rapid abatement of the other prominent symptoms of the disease. I shall, however, give a complete history of this case in a subsequent communication.t I have no doubt that others will,

* Cases of Diabetes Mellitus. London, 1799 and 1806.

+ Cyclopædia of Practical Medicine, vol. i., p. 515 .

\& Since writing the above, $I$ have commenced the treatment of another case of long standing. In this the urine was reduced from 26 pints, sp. gr. on trial, find the remedy to act with the same magical rapidity as I have done.

But that milk should exercise a more powerful influence over diabetes than even a purely animal diet can, I think, be explained by the fact that the caseine of milk, being a primitive albumen, is infinitely superior, as an agent of nutrition, to the albumen of muscle, which has been highly and specially organised to perform an important vital function. Besides, the sugar which milk contains is quite innocuous in the disease (as shown by my experiments), and it supplies the system with a saccharine, proximate, alimentary principle equivalent to such as is afforded by vegetable food. There can be no doubt that the sugar of milk is destined to supply for the nutrition of the young an equivalent for the amylaceous and saccharine principles entering so largely into the food of the adult.

It is erroneous to suppose that a moderate quantity of sugar is injurious in diabetes. Sugar cannot be again converted into sugar by any morbid process in operation in the liver or elsewhere, and cannot therefore supply a pabulum for the activity of the morbid process by which diabetic sugar is elaborated. Starch seens to be the fuel requisite to maintain the morbid action of the disease in all but the most advanced cases, and it would appear that this substance, and every species of food containing it, should be prohibited, even in complete recoveries, for a long period after health has been re-established, and sugar long absent from the urine. The necessity of this precaution was shown in the case of the youth, T. H - who, before he left the infirmary, clandestinely partook of large quantities of bread. the result being that some sugar reappeared in the urine: but in three days this again totally disappeared, after bread had been strictly prohibited. In some individuals the tendency to the formation of sugar, from the malassimilation of amylaceous substances, may possibly be so great as to become an idiosyncrasy. But what length of time must elapse before permanent security is reached can only be ascertained by direct experiment; doubtless it will be found to vary much in individual cases.

The success of the milk treatment of diabetes shows that in this disease it is by no means necessary to limit the quantity of fluid taken by the patient, as has been supposed by some authorities. The thirst bears a definite relation to the quantity of saccharine urine voided, and rapidly subsides when the latter has been reduced to a nearly normal condition.

These observations will, I trust, stimulate others to investigate the subject for themselves. I shall only add that in all probability milk will be found, from the nature of the organic compounds it contains, to be the most potent remedy we shall ever become acquainted with in the treatment of diabetes mellitus.

(To be continued.)

\section{CASE OF INTUSSUSCEPTION TREATED BY INFLATION AND DISTENSIVE ENEMA}

\author{
RECOVERY ; REMARKS.
}

\section{By GEORGE EASTES, M.B., F.R.C.S.}

(Coneluded from p.670.)

Is reference to the report of this case, which appeared in The Lancer of Nov. 13th, many points of interest suggest themselves, capable of arrangement under three heads.

Diagnosis.-The distension of abdomen and paroxysmal character of the pain located the lesion about the intestinal tube itself; whilst the fact of this tympanitic distension being confined to the lower part of the belly, and not implicating the colon-the sudden appearance of the tumour in the right iliac fossa, where it was immovable, evidently intra-abdominal, and in its cylindrical form and position coincided with such a tumour as would be produced by the reception of a portion of the ileum and the cæcum into the lower two-thirds of the ascending colon,- and perhaps the

the end of three days; and this with a correspondingly rapid improvement in the general symptoms. 
jurenility of the patient,-all these circumstances pointed unmistakably to intussusception, and to that variety of the disease in which the smaller bowel is received into the larger. Any doubt I had arose from the fact that, upon my questioning her, the girl's mother stated that she had seen the pan after each relief of the bowels during and after the evening of April 24th, when the severe colicky pain began, and she was sure that on no occasion was any blood passed per rectum. I was then under an impression, from my remembrance of a paper by Mr. Gorham in the Guy's Hospital Reports, Series i., vol. iii., that hæmorrhage is a constant and early symptom of the disorder; but I have since had reason to modify the opinion very considerably. Dr. Brinton gives amongst the symptoms distinctire of ileocolic from simple iliac intussusceptions the "subordinate share taken in the former variety by hæmorrhage, which often is scarcely sufficient to tinge the mucus passing from the bowels." * In each of nine cases of ileo-colic intussusception in children under one year of age, tabulated by Mr. Gorham, hæmorrhage was present; but there was no appearance of blood in two adults, patients of $\mathrm{Mr}$. Birlkett. $\uparrow$ As I was responsible for the report of one of these two cases, and the paper containing them is ready to my hand, I instance them before others. And, indeed, the verdict of other observers is, that in infancy hæmorrhage almost invariably occurs, whilst in later life it may or may not be present. I have discussed this matter at such length because the diagnosis forms the key of the whole case. Upon its correctness hinges, not only the propriety of the treatment here adopted, but also the value of the case as an example of benefit thereby produced.

Progress of the case. It would appear, from a careful perusal of the foregoing report, that the disease commenced on April 19th, with uneasiness and pain in the belly, and disturbance of physiological processes in neighbouring organs-e. g., retention of urine. I imagine that a slight ileo-colic invagination then occurred, inappreciable by palpation through the abdominal parietes; that it became increased during, and by, the vomiting on the 24th, at 10 P.M. Strangulation of the intussuscepted bowel does not seem to have supervened until the night between the 25 th and $26 \mathrm{th}$, when persistent vomiting began. This is the usual course of the disease, and the fact should make one very careful in the administration of purgatives for the relief of any spasmodic abdominal pain, especially in children or young persons, lest, if the colic be due to a commencing intussusception, the malady be aggravated by the exhibition of such medicines. The tumour, which on April 21st was just above the pubes, was certainly the distended bladder, the result of retention during seventeen and a half hours. Unfortunately for the purposes of positive diagnosis, micturition was performed in the bath. With relief of the bladder symptoms disappeared the rapidity of pulse and pain and tumefaction of the abdomen. There was, in fact, subsidence of all local symptoms from the 21 st to the 24 th, which also is frequently noticed.t

rreatment.-Beyond keeping the patient at perfect rest in the recumbent posture, giving milk or other easily digestible fluid nourishment, in small and oft-repeated quantities-that is, none other than the ordinary hygienic measures suitable for strangulated bowel,-only two kinds of treatment at present find favour-sedatives and inflation or distensive enemata. As reoards drugs, opium is given in all cases with the happiest of effects; and where the stomach rejects everything, the hypodermic method of administration should be practised. Tobacco is probably now rarely used; and only one other drug need be mentioned. Dr. Brinton's views of the value of the combination of opium and belladonna seem not sufficiently widely known. I make this excuse for their introduction here. Condensed from his own words, they are as follows:- "The sufferings and lesions produced by intussusception depend, in great degree, upon the terrible forcing contractions of the intruded bowel. Now, opium (which causes contraction of the unstriped muscle in the eye, and tetanises the voluntary striped muscles of many vertebrata) may be pushed to the verge of producing complete narcotism without diminution of this agonising straining peristalsis. The combination of belladonna with opium seems no way to lessen the anodyne

* Intestinal Obstruction, edited by Dr. Buzzard, p. 58 .

+ Gug's Hospital Reports, Series iii., rol. xiii.

t Hilton Fagge on Intestinal Obstruction. Guy's Hospital Reports, effect of the latter drug, even while it reduces the peristalsis almost to a zero. The proportions I use are two parts of extract of opium to one, two-thirds or one-half part of extract of belladonna, in a pill." *

But observers differ widely in their estimate of treatment by inflation or forcible esemata. The perusal of Mr. Gorham's above-cited paper first directed my attention to the subject, and I determined to practise his suggestions the first time a suitable case for treatment came under my notice. Here was the opportunity, and the result justified the experiment. Nerertheless, it seems right to lay down rules for the use of a measure so potent for good or ill. The anatomical couditions of the ileo-cacal valve, preventing the passage of fiut from the colon to the ileum, at once exclude from this treatment all cases except those of the colic or ileo-cwcal variety of the disease-those, in fact, in which the large intestine is implicated, and which form 68 (ileo-cæeal 56, colic 12) per cent., or a little more than the two-thirds majority, of all cases. Notwithstanding, where it is doubtful if the intussusception has passed the ileococal valve, or is confined exclusively to the small intestine, an injection should be given, as it may do good, and, with proper precautions, cannot harm.

But, limited as we are to cases, I believe we must be still more limited to time. For, a distensive enema administered some days after strangulation by intussusception, and where the united entering and returning piece of bowel is commencing to be cast of by slough, would in all probability produce perforation and rapid death. Fortunately, it is in the larger class of ileo-colic cases that the symotoms usually run a cradual course, invagination and consequent abdominal tumour existing for weeks or even months before the supervention of strangulation; though "sometimes strangulation occurs at the first onset, and death within three or four days." + Pressure upon the impacted intestine, in the ileo-colic disease, seems generally at first to be inconsiderable, as is proved by two facts: hæmorrhage, as already stated, is not always present; and the date of expulsion of sloughed invaginated segments does not, on the average, take place until the fifteenth and twenty-second days, instead of the eighth and tenth respectively, as in the intussuscepted small intestine.t Hence, further, if all other signs and symptoms betoken invagination in the large bowel, the fact of no blood or bloody mucus passing away not only does not contraindicate the ase of the enema, but even favours recourse to such treatment, indicating, as it seems to do, the less severity of the constriction, and offering greater probability of release of the intussusception. I should not, in any future case, inject (for distensive purposes) after the lapse of about seventy hours from the beginning of constitutional symptoms, the case running a moderately severe course; and, the constitutional symptoms being very urgent, I should think the period for injection gone by if more than half that time had elapsed. It is impossible to lay down rules always applicable or more definite, because of the variation in progress which ileo-colic cases exhibit. The mechanical trestment, to be efficient, must be adopted early (if possible, before the occurrence of strangulation), and should not be postponed one hour after the diagnosis is settled; because, with the lapse of time, that which is merely a slight invagination may enlarge or become a strangulation; whilst, if the intestine be already strangulated, adhesions are in process of formation, and the contained bowel is becoming swollen and rapidly undergoing changes to permit of its being cast off.

Shall a liquid or air be injected? The latter was certainly of less use in this case than the former, and it may be that by a liquid the bowel is more readily reducible than by air, whilst the former seems to the patient the more formidable agent. The fact, mentioned in the report, that some twelve to eighteen ounces of the injected water were altogether retained, recalls special attention to a remark by Dr. Brinton, that "admixture with milk or gruel confers upon enemata a further contingent usefulness by permitting: an absorption of some constituents of food." (p. 111.) Restricting, then, its employment within the above-assigned limits, I believe we have in forcible injection a very efficient therapeutical agent. It should be administered with great caution by the surgeon himself, who should occupy some

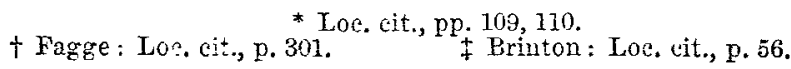


time in the operation, that the gut may become accustomed to the fluid or air already injected before an additional syringeful is pumped in. Full distension must be kept up for some time; and the operation may be shortly repeated should the first be followed by no immediate benefit. Also it must not be overlooked that the procedure is much facilitated by the use of chloroform.

Bearing these several points in mind, I should inflate first, especially if consulted early in a case; and, if no amendment resulted, I would use, after a few hours, a distensive enema of lukewarm milk or milk-and-water. At the same time, for medical treatment until reduction of the intussusception, I would combine belladonna with opium. Albion-place, Hyde-park-square, Nov. 1869.

\section{A STUDENT'S THOUGHTS ON MEDICAL EDUCATION.*}

BY EDGAR G. BARNES, EsQ.

(Communicated by Bernard Brodherst, Esq.)

THE object of medical education I take to be to train a student in such a manner that when he is sent forth as a legally qualified medical man, be he a general practitioner or a specialist, he may practise not only with safety but with benefit to his patients, and with credit to himself and to his teachers. I purpose therefore to consider how our existing hospitals and medical schools may be better fitted to fulfil this purpose. The opinions I shall state to-night will be, I hope, freely discussed, for in this subject there is an immense latitude for difference of opinion.

The first proposal, then, I have to make is to lessen "the amount of compulsory attendance on lectures." Some men nowadays tell us that lectures are of no use, and would do away with them altogether; others tell us that they are the most powerful agents of teaching we possess. I think this ciscrepancy of opinion arises from the different constitution of men's minds. "What is one man's meat is another man's poison" is an adage which will be found to hold good on this point, as well as on many others. In my mind some lectures are unquestionably of great use; on the other hand, I am equally convinced that some are utterly useless. If the student were allowed to use his own discretion as to the particular courses of lectures he attends-if, in fact, the regulation which exists at the University of London were the rule of all the examining bodies-namely, to compel the student to attend a few courses of lectures, and to give him a long list of subjects from which he might pick whatever lectures he pleased to attend,- I believe then those lectures which are really instructive would be attended quite as fully as they are now, and those lectures which are uninstructive would not be so attended, and the student would be spared the painful necessity of sitting hour after hour and day after day to hear a long monotonous list of dry details, in which he takes no interest, and which (to use a homely phrase) "go in at one ear and out at the other."

I would also re-echo the suggestion which has been made " to do away with compulsory attendance on second courses of lectures." If, indeed, the student gains instruction from any lectures, and wishes to attend them again, by all means leave him at liberty to do so again and again, as often as he pleases. What I am endeavouring to argue is: let the student's knowledge be tested as rigidly as you please by $\in \mathrm{x}-$ aminations, but give him latitude in the means by which he attains that knowledge. So long as he attains the amount necessary for the practice of his profession, it appears to mo perfectly immaterial how he attained it, whether by attending five courses of lectures or thirty. To dictate the exact course a student must follow throughout his entire career, to lay down laws from which he must not swerve a hair's breadth to the right hand or the left, seems unnecessary. The plan may be admirable; it may be adapted to the constitution of the minds of the majority of men; yet, why should that unhappy minority who possess differently-constituted minds be compelled wearily to trudge along a road which, at the best, brings them but slowly to

\footnotetext{
* A paper read before the St. George's Hospital Medical Society.
}

their journey's end? To make all students follow the same course seems to be the same in principle as to treat all the cases of the same disease by the same method, to pay no attention to the strength and constitution of the patient, nor to the special symptoms belonging to each case. Under the present management, a student going in for the Mem. bership of the College of Surgeons has, during his first two years, to attend lectures varying in number, according to the hospital at which he may be placed, from 1461 at University College to 793 at Westminster, as will be seen by this table, which I have compiled from the prospectuses of the different Schools:-

TABLE I.-Showing the amount of COMPULSORY attendance at lectures during the first two years at the different medical schools.

\section{MEDICLI SCHOOL.}

Number of

$$
\begin{gathered}
\text { lectures } \\
\text { to be }
\end{gathered}
$$

to be
attended in

ist year.

ist year.
631
593

Number of lectures

ttended in

2nd year.

1. University College

$\begin{array}{lllll}\text { Sing's College } & \ldots & \ldots & \ldots & 593 \\ \text { St. Ilary's } & \ldots & \ldots & 41.6\end{array}$

$\begin{array}{lllll}\text { 3. } & \text { St. Bary's } \ldots & \ldots & \ldots & 416 \\ \text { 4. } & \text { St. Bartholomew's } & \ldots & 398\end{array}$

5. Charing-cross $\ldots . . . .384$

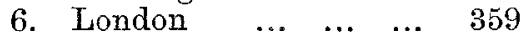

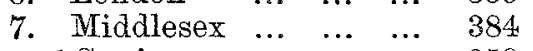

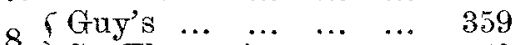

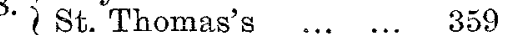

10. St. George's $\quad \ldots .6$.

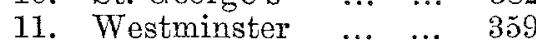

830
545

545

594

ธ08

508

496

507

471

483

... 483

446

434

Total of the years of study.

study

1138

1040

906

880

866

855

842

842

793

Surely this is too much to require in addition to dissections, practical chemistry, practical botany, demonstrations on the microscope, examinations, and hospital practice both medical and surgical.

Before leaving the subject of lectures, I would express my opinion that all lectures should be made as attractive as possible, by illustrating them by drawings, diagrams, preparations, and experiments. Some lecturers do this well enough; others, to say the best, indifferently; yet I think most of you will agree with me that to listen to an hour's abstract reasoning, delivered perhaps in a monotonous tone of voice, without the slightest attempt to illustrate it, and to render it interesting, has a very decided soporific effect, if one may judge by the nodding heads to be sometimes seen on looking round the lecture-room.

The next point to which I would turn your attention is to the method of teaching by examination. I look upon this as (for the majority of students) one of the most effcient, I am not sure I ought not to say the most efficient, method of teaching. I believe it is carried out pretty well at all our medical schools as regards the subject of anatomy; and I consider the appointment of a medical tutor here and at several other hospitals as a decided step in the right direction towards applying the plan to other subjects. But I would suggest that it would be well to carry it still further: that each lecturer ought himself to examine on the subject of his course; that one lecture out of every three should be devoted to examination. This plan wonld not increase the lecturer's labour, and it would not increase the work of the student; 5 et I believe it would form a more efficient plan than that which is adopted by too many lecturers of going straight through a subject without once giving a thought to what has gone before. I believe that this method of examination-of making mistakes oneself and of hearing others make them, of raising a laugh at one's own expense and of joining in a laugh created by another-is a method by which much may be learned; and, besides, it has the advantage of provoking emulation and stimulating students to work; for we all have some pride, and do not like to make ourselves conspicuous for our want of knowledge when we can possibly avoid it. I should, however, allow in this the same option as $I$ should in attending lectures, for some men I know have a decided objection to being publicly examined.

I should next suggest the importance of practical courses. Their use is already recognised to a much greater extent than it was a few years ago. In these I should not allow that option which I have recommended in the case of lectures and examinations; for, as the main object of medical education is to fit men to practise medicine as an art, I consider there cannot be any doubt that practical instruction 